\title{
CLINICAL PRESENTATION, ETIOLOGY AND OUTCOME OF UPPER GASTROINTESTINAL BLEED FROM A TERTIARY CARE HOSPITAL OF EAST SIKKIM: AN OBSERVATIONAL STUDY.
}

Lok Bahadur Limboo, Mona Dhakal, O P Dhakal

1. Senior Resident, Department of Medicine. Sikkim Manipal Institute of Medical Sciences and Central Referral Hospital.

2. Associate Professor, Department of Medicine. Sikkim Manipal Institute of Medical Sciences and Central Referral Hospital.

3. Associate Professor, Department of Medicine. Sikkim Manipal Institute of Medical Sciences and Central Referral Hospital.

\section{CORRESPONDING AUTHOR:}

O. P. Dhakal.

Associate Professor, Dept of Medicine,

Sikkim Manipal Institute of Medical Sciences and,

Central Referral Hospital,

(CRH). $5^{\text {th }}$ mile Tadong, Gangtok, Sikkim-737102.

E-mail: opdhakal@gmail.com

\begin{abstract}
Upper gastrointestinal bleeding refers to blood loss within the intraluminal gastrointestinal tract from any location between the upper oesophagus to the duodenum at the level of the ligament of treitz. [1] It is a common medical emergency associated with significant morbidity and mortality. [2,3] Bleeding from the upper gastrointestinal tract is approximately five times more common than lower gastrointestinal tract. [4] The common causes include duodenal ulcer, gastric ulcer, erosive mucosal disease, varices of portal hypertension and Mallory Weiss syndrome. Less common causes include esophagitis, neoplasm and angiodysplasia. [5] Bleeding from the gastrointestinal tract may present as hematemesis, maelena, hematochezia, occult gastrointestinal bleeding, and anaemia. [6]

The overall incidence of acute upper gastrointestinal hemorrhage has been estimated at 50 to 100 per 100,000 patients per year, with an annual hospitalization rate of approximately 100 per 100,000 hospital admissions. [7, 8] The incidence of upper gastrointestinal bleeding is increasing in elderly people; one study found that those over 65 years of age comprised over $30 \%$ of those with upper gastrointestinal bleeding. [9]
\end{abstract}

AIMS AND OBJECTIVES: To study clinical presentation, identify the etiology and to assess the hospital outcome of upper gastrointestinal bleed patients admitted in Department of Medicine, Central Referral Hospital, Gangtok.

OBSERVATIONS: In the above study maximum patient were in the age group of 51-60 years with mean age of 53.70years. There were no patients below 20 years and above 90 years. Male (72.9\%) were affected more than the female (27.1\%). Most common presenting complaints were maelena in $40(57.1 \%)$, hematemesis in $17(24.2 \%)$ patients. History of intake of aspirin was more common in female than male. Similarly NSAIDS intake history was common in male than in female. Regular 


\section{ORIGINAL ARTICLE}

alcohol intake was seen in 40 (57.1\%) , 19 (27.1\%) occasional, 2 (2.8\%) ex alcoholic patients and 9 (12.8\%) non alcoholic patient in the study. 23 (32.8\%) were regular smoker, 12 (17.1\%) ex-smoker and $6(8.5 \%)$ occasional smoker. There was no history of smoking in $6(8.5 \%)$ patients. Smoking habits was more common in males as compare to females. Non-vegetarian 58 (82.85\%) and vegetarian diet 12 (17.1\%). In the above study maximum patient had oesophageal varices 26 (37.1\%) as the cause of bleeding followed by duodenal ulcer and erosive mucosal disease $11(15.7 \%)$ each. Gastric ulcer were the cause on $8(11.4 \%)$ patients and esophagitis were present on 7 (10\%). Portal gastropathy was present on 5 (7.1\%) and tumors on 2 (2.8\%). Average duration of stay in hospital was 8.2 days. The minimum and maximum duration of hospital stay were 4 and 20 days respectively. 41(58.5\%) improved with medication and 25 (35.7\%) patients required endoscopic intervention in form of banding, sclerotherapy, Out of 70 patients 2 (2.8\%) were referred and another 2 (2.8\%) patient expired.

CONCLUSION: The above study conducted over a span of one year from $1^{\text {st }}$ June 2010 to $31^{\text {st }}$ May 2011 among the patient of upper gastrointestinal bleeding has revealed that esophageal varices was the commonest cause of upper gastrointestinal bleeding in Sikkim. It is followed by peptic ulcer disease and erosive mucosal disease. Increasing trend of esophageal varices is probably due to alcohol abuse leading to alcoholic cirrhosis and various other causes. In addition to that due to overuse of proton pump inhibitors and declining H. pylori infection has decreased the prevalence of peptic ulcer disease as compare to some study from western countries.

INTRODUCTION: Upper gastrointestinal bleeding refers to blood loss within the intraluminal gastrointestinal tract from any location between the upper oesophagus to the duodenum at the level of the ligament of treitz. [1] It is a common medical emergency associated with significant morbidity and mortality. [2,3] Bleeding from the upper gastrointestinal tract is approximately five times more common than lower gastrointestinal tract. [4] The common causes include duodenal ulcer, gastric ulcer, erosive mucosal disease, varices of portal hypertension and Mallory Weiss syndrome. Less common causes include esophagitis, neoplasm and angiodysplasia [5] Bleeding from the gastrointestinal tract may present as hematemesis, maelena, hematochezia, occult gastrointestinal bleeding, and anaemia. [6]

The overall incidence of acute upper gastrointestinal hemorrhage has been estimated at 50 to 100 per 100,000 patients per year, with an annual hospitalization rate of approximately 100 per 100,000 hospital admissions. [7, 8] The incidence of upper gastrointestinal bleeding is increasing in elderly people; one study found that those over 65 years of age comprised over $30 \%$ of those with upper gastrointestinal bleeding. [9]

The incidence of upper gastrointestinal bleeding is 2-fold greater in males than in females, in all age groups, however, the death rate is similar in both sexes. [10] Mortality increases with older age (>60 y) in males and females. [11]

Acute gastrointestinal bleeding occurs frequently, prompting hospital admission or complicating another illness. With a systematic management approach, nine out of ten patients with massive upper gastrointestinal bleed can be saved. [12] Despite advances in critical care monitoring and support, mortality rates of $10 \%$ to $20 \%$ continue to be reported. $[13,14]$ While spontaneous cessation of bleeding occurs in as many as $85 \%$ of cases and early intervention is required in those 
in whom bleeding does not stop spontaneously. $[15,16]$ Endoscopic diagnosis and therapy is now an integral part of the management of these patients.[17] Within 12-24 hours of admission, endoscopy will detect the cause of haemorrhage in about $80 \%$ or more if performed expertly. [18]

The incidence of upper gastrointestinal bleeding is 2-fold greater in males than in females, in all age groups; however, the death rate is similar in both sexes. [19] Mortality increases with older age (>60 y) in males and females. [20]

A study by A R M Saifuddin Ekram et al, Bangladesh has revealed that hematemesis and maelena (42\%), only maelena (42\%) and only hematemesis (16\%) as the presenting features.[21] A study of clinical profile of acute upper gastrointestinal bleeding by Lal Singh Pal et al, has revealed that both hematemesis and maelena (56.8\%), only hematemesis (28\%) and only maelena (14.4\%) as the clinical presentation. [22] A study by Bedi TRS et al, Kathmandu, Nepal found hematemesis (56.7\%), maelena (14.4\%), recent onset anaemia with positive occult blood $(22.2 \%)$ and both haemetemesis and maelena (6.7\%) as presenting features.[23] Another study from northwestern Tanzania by Hyasinta et al found that the vast majority of patient presented with hematemesis $(80.4 \%)$ alone. Maelena alone was reported in $9.2 \%$ patients. Both hematemesis and maelena (5\%) and hematochezia (0.8\%) were other presenting features. [24] A study by C. Sugawa et al, Michigan has revealed the presenting complaints as hematemesis (58\%), maelena (45\%), nasogastric aspirate containing blood or clot (19\%), syncope (12\%) and hematochezia (10\%).[25] Gastroduodenal ulcer disease remains a common cause of upper gastrointestinal bleeding.[26] There are four major risk factors for bleeding peptic ulcers.[27,28]

Through the various recent advances in medication and endoscopy, the identification of etiology, clinical profile and outcome provides a significant opportunity to reduce the burden of morbidity and mortality due to upper gastrointestinal haemorrhage. Research oriented study regarding the clinical profile, etiology and outcome of upper gastrointestinal bleeding patient is lacking. Systemic approach on this front could add to the background data in the mind of the clinician treating such patients. In the long run, the result of this study conducted in Sikkim could be compared with data from similar studies conducted elsewhere and this would lead to the enhancement of knowledge regarding clinical profile, etiology and outcome of upper gastrointestinal bleed patient.

AIMS AND OBJECTIVES: To study clinical presentation, identify the etiology and to assess the hospital outcome of upper gastrointestinal bleed patients admitted in Department of Medicine, Central Referral Hospital, Gangtok.

OBSERVATIONS: Observations are presented as tables.

TABLE 1: Showing age and gender distribution.

\begin{tabular}{|l|l|l|l|l|} 
Gender & Mean Age & Total Patients (70) & Minimum Age & Maximum Age \\
Male & 55.00 & $51(72.85 \%)$ & 28 & 82 \\
\hline Female & 50.21 & $19(27.14 \%)$ & 28 & 72 \\
\hline
\end{tabular}

TABLE 2: Showing age wise distribution of presenting complaint 


\section{ORIGINAL ARTICLE}

\begin{tabular}{|c|c|c|c|c|c|c|c|c|}
\hline \multirow[t]{2}{*}{ Presenting complaints } & \multicolumn{7}{|c|}{ Age Group } & \multirow[b]{2}{*}{ Total (70) } \\
\hline & $21-30$ & $31-40$ & $41-50$ & $51-60$ & $61-70$ & $71-80$ & $81-90$ & \\
\hline Hematemesis & 0 & 3 & 1 & 7 & 4 & 1 & 1 & $17(24.29 \%)$ \\
\hline Maelena & 2 & 8 & 8 & 10 & 7 & 5 & 0 & $40(57.14 \%)$ \\
\hline Both Hematemesis and Maelena & 0 & 3 & 4 & 3 & 1 & 2 & 0 & $13(18.57 \%)$ \\
\hline
\end{tabular}

TABLE 3: Showing drug history in different gender.

\begin{tabular}{|l|l|l|l|}
\hline \multirow{2}{*}{$\begin{array}{l}\text { DRUG } \\
\text { HISTORY }\end{array}$} & \multicolumn{2}{|l|}{ Gender } & \multicolumn{1}{|l|}{ Total (70) } \\
\hline & male & female & Totan \\
\hline NSAIDS & 4 & 3 & $7(10.00 \%)$ \\
\hline ASPIRIN & 2 & 7 & $9(12.86 \%)$ \\
\hline Others drug & 39 & 7 & $46(65.71 \%)$ \\
\hline $\begin{array}{l}\text { No } \\
\text { history }\end{array}$ & & & $8(11.43 \%)$ \\
\hline
\end{tabular}

TABLE 4: Showing alcohol history in different age-group

\begin{tabular}{|l|l|l|l|l|l|l|l|l|}
\hline & Alcohol history & Age Group & \multicolumn{1}{l|}{} \\
\cline { 1 - 7 } & $21-30$ & $31-40$ & $41-50$ & $51-60$ & $61-70$ & $71-80$ & $81-90$ & Total (70) \\
\hline Regular & 0 & 9 & 8 & 11 & 6 & 6 & 0 & $40(57.14 \%)$ \\
\hline Ex-alcoholic & 0 & 0 & 1 & 1 & 0 & 0 & 0 & $2(2.86 \%)$ \\
\hline Occasional & 1 & 4 & 1 & 6 & 5 & 1 & 1 & $19(27.14 \%)$ \\
\hline Non Alcoholic & 1 & 1 & 3 & 2 & 1 & 1 & 0 & $9(12.86 \%)$ \\
\hline
\end{tabular}

TABLE 5: Showing smoking history in different gender group.

\begin{tabular}{|l|l|l|l|}
\hline Smoking History & \multicolumn{2}{|l|}{ Gender } & \multicolumn{1}{l|}{ Total (70) } \\
\hline & male & female & Tota \\
\cline { 1 - 3 } Regular Smoker & 21 & 2 & $23(32.86 \%)$ \\
\hline Ex-smoker & 11 & 1 & $12(17.14 \%)$ \\
\hline Occasional & 6 & 0 & $6(8.57 \%)$ \\
\hline Non Smoker & 13 & 16 & $29(41.43 \%)$ \\
\hline
\end{tabular}

TABLE 6: Showing stool for occult blood in different gender 


\section{ORIGINAL ARTICLE}

\begin{tabular}{|l|l|l|l|}
\hline Stool For OBT & \multicolumn{2}{|l|}{ Gender } & \multicolumn{1}{l}{} \\
\cline { 1 - 2 } & male & female & Total (70) \\
\hline Positive & 21 & 4 & $25(35.71 \%)$ \\
\hline Negative & 30 & 15 & $45(64.29 \%)$ \\
\hline
\end{tabular}

TABLE 7: Showing dietary habits in different age-groups

\begin{tabular}{|c|c|c|c|c|c|c|c|c|}
\hline \multirow[b]{2}{*}{ Diet } & \multicolumn{7}{|c|}{ Age Group } & \multirow[b]{2}{*}{ Total (70) } \\
\hline & $21-30$ & $31-40$ & $41-50$ & $51-60$ & $61-70$ & $71-80$ & $81-90$ & \\
\hline Vegetarian & 0 & 3 & 3 & 2 & 2 & 2 & 0 & $12(17.14 \%)$ \\
\hline Non-vegetarian & 2 & 11 & 10 & 18 & 10 & 6 & 1 & $58(82.85 \%)$ \\
\hline
\end{tabular}

TABLE 8: Showing blood groups in different age-groups.

\begin{tabular}{|l|l|l|l|l|l|l|l|l|}
\hline BLOOD GROUP & Age Group & \multirow{2}{*}{} \\
\cline { 1 - 8 } & $21-30$ & $31-40$ & $41-50$ & $51-60$ & $61-70$ & $71-80$ & $81-90$ & Total (70) \\
\hline A+ & 0 & 5 & 1 & 5 & 4 & 4 & 1 & $20(28.57 \%)$ \\
\hline B+ & 0 & 3 & 5 & 9 & 8 & 2 & 0 & $27(38.57 \%)$ \\
\hline AB+ & 0 & 2 & 1 & 3 & 0 & 1 & 0 & $7(10.00 \%)$ \\
\hline O+ & 1 & 3 & 6 & 3 & 0 & 1 & 0 & $14(20.00 \%)$ \\
\hline A- & 0 & 1 & 0 & 0 & 0 & 0 & 0 & $1(1.43 \%)$ \\
\hline B- & 1 & 0 & 0 & 0 & 0 & 0 & 0 & $1(91.43 \%)$ \\
\hline
\end{tabular}

TABLE 9: Showing the USG Findings.

\begin{tabular}{|l|l|l|l|l|l|l|l|l|}
\hline Ultrasonography of Abdomen & \multicolumn{7}{|l|}{ Age Group } & \multirow{2}{*}{} \\
& $21-30$ & $31-40$ & $41-50$ & $51-60$ & $61-70$ & $71-80$ & $81-90$ & Total (70) \\
\hline Liver Cirrhosis & 0 & 6 & 5 & 8 & 4 & 4 & 0 & $27(38.57 \%)$ \\
\hline Other than liver cirrhosis & 0 & 3 & 1 & 2 & 3 & 2 & 0 & $11(15.71 \%)$ \\
\hline Normal Study & 2 & 5 & 7 & 10 & 5 & 2 & 1 & $32(45.71 \%)$ \\
\hline
\end{tabular}

TABLE 10: Showing the findings by upper GI endoscopy in different age groups. 
ORIGINAL ARTICLE

\begin{tabular}{|l|l|l|l|l|l|l|l|l|}
\hline Etiology by Endoscopy & \multicolumn{7}{|l|}{ Age Group } & \multicolumn{1}{l|}{ The } \\
\hline & $21-30$ & $31-40$ & $41-50$ & $51-60$ & $61-70$ & $71-80$ & $81-90$ & Total(70) \\
\hline Duodenal Ulcer & 0 & 1 & 5 & 3 & 1 & 1 & 0 & $11(15.71 \%)$ \\
\hline Gastric Ulcer & 0 & 2 & 1 & 1 & 3 & 1 & 0 & $8(11.42 \%)$ \\
\hline Esophageal Varices & 0 & 6 & 4 & 8 & 4 & 4 & 0 & $26(37.14 \%)$ \\
\hline Esophagitis & 0 & 2 & 1 & 2 & 1 & 0 & 1 & $7(10 \%)$ \\
\hline Erosive Disease & 2 & 1 & 0 & 4 & 2 & 2 & 0 & $11(15.71 \%)$ \\
\hline Tumors & 0 & 0 & 0 & 1 & 1 & 0 & 0 & $2(2.85 \%)$ \\
\hline Portal Gastropathy & 0 & 2 & 2 & 1 & 0 & 0 & 0 & $5(7.14 \%)$ \\
\hline
\end{tabular}

TABLE 11: Showing findings by endoscopy in different gender.

\begin{tabular}{|l|l|l|l|}
\hline Etiology by Endoscopy & \multicolumn{2}{|l|}{ Gender } & \multicolumn{1}{l}{} \\
\cline { 1 - 3 } & male & female & TOTAL(70) \\
\hline Duodenal Ulcer & 5 & 6 & $11(15.71 \%)$ \\
\hline Gastric Ulcer & 3 & 5 & $8(11.42 \%)$ \\
\hline Esophageal Varices & 21 & 5 & $26(37.14 \%)$ \\
\hline Esophagitis & 7 & 0 & $7(10 \%)$ \\
\hline Erosive Mucosal Disease & 8 & 3 & $11(15.71 \%)$ \\
\hline Tumors & 2 & 0 & $2(2.85 \%)$ \\
\hline Congestive Gastropathy & 5 & 0 & $5(7.14 \%)$ \\
\hline
\end{tabular}

TABLE 12: Showing duration of stay in hospital.

\begin{tabular}{|l|l|l|l|}
\hline & Minimum & Maximum & Mean \\
\hline $\begin{array}{l}\text { Duration of stay in hospital (in } \\
\text { days) }\end{array}$ & 4 & 20 & 8.2 \\
\hline & & & \\
\hline
\end{tabular}

TABLE 13: Showing outcome at discharge of different age groups.

\begin{tabular}{|l|l|l|l|l|l|l|l|l|l|}
\hline Outcome at discharge & \multicolumn{3}{l|}{ Age Group } & \multicolumn{1}{l|}{} \\
\hline & $21-30$ & $31-40$ & $41-50$ & $51-60$ & $61-70$ & $71-80$ & $81-90$ & Total (70) \\
\hline $\begin{array}{l}\text { Improved with conservative treatment } \\
\begin{array}{l}\text { Requirement of endoscopic intervention } \\
\text { Referred out. }\end{array}\end{array}$ & 2 & 8 & 9 & 11 & 6 & 4 & 1 & $41(58.57 \%)$ \\
Expired & 0 & 5 & 4 & 8 & 4 & 4 & 0 & $25(35.71 \%)$ \\
\cline { 2 - 12 } & 0 & 0 & 0 & 1 & 1 & 0 & 0 & $2(2.85 \%)$ \\
\cline { 2 - 11 } & 0 & 1 & 0 & 0 & 1 & 0 & 0 & $2(2.85 \%)$ \\
\hline
\end{tabular}

TABLE 14: Showing outcome at discharge of different gender. 


\section{ORIGINAL ARTICLE}

\begin{tabular}{|l|l|l|}
\hline Outcome at the discharge & Gender (total 70) \\
\hline $\begin{array}{l}\text { Improved with conservative } \\
\text { treatment }\end{array}$ & Male (51) & Female (19) \\
\hline $\begin{array}{l}\text { Requirement of endoscopic } \\
\text { intervention }\end{array}$ & $20(39.90 \%)$ & $13(68.42 \%)$ \\
\hline Referred & $2(3.92 \%)$ & $5(26.31 \%)$ \\
\hline Expired & $1(1.96 \%)$ & $0(0 \%)$ \\
\hline
\end{tabular}

DISCUSSIONS: Acute gastrointestinal bleeding is one of the serious gastrointestinal medical emergency. Acute upper gastrointestinal bleeding is associated with considerable morbidity and mortality rates (13\%), as well as the enormous financial burden on health services.[29] Patients with severe acute gastrointestinal bleeding are seriously ill and require proper assessment and intensive monitoring of their vitals and clinical progress.[30] Urgent endoscopy in is an essential part of a medical care. It is not only reliable in identifying the cause of bleeding, but it enables to start therapeutic intervention immediately and assessing the prognosis of a patient.[31] The result were obtained and compared with the available literature. In the above study maximum patient were in the age group of 51-60 years with mean age of 53.70years. There were no patients below 20 years and above 90 years. Male (72.9\%) were affected more than the female (27.1\%). Most common presenting complaints were maelena in 40 (57.1\%), hematemesis in $17(24.2 \%)$ patients. There was history intake of NSAIDS in 7 (10\%) patients, Aspirin in 9 (12.8\%), other medicines in 8 (11.4\%). No medication in $46(65.7 \%)$ patients. History of intake of aspirin was more common in female than male. Similarly NSAIDS intake history was common in male than in female. Regular alcohol intake was seen in $40(57.1 \%), 19$ (27.1\%) occasional, 2 (2.8\%) ex alcoholic patients and 9 (12.8\%) non alcoholic patient in the study. 23 (32.8\%) were regular smoker, 12 (17.1\%) ex-smoker and 6 (8.5\%) occasional smoker. There was no history of smoking in $6(8.5 \%)$ patients. Smoking habits was more common in males as compare to females. Non-vegetarian were $58(82.85 \%)$ and vegetarian diet were 12 (17.1\%). The blood group B+ was $27(38.5 \%)$ and was the most common blood group. Least common blood group was A- (1.4\%) and B- (1.4\%). Stool for occult blood were positive in 25 $(35.7 \%)$ patients and was negative in $45(64.2 \%)$ patients. In the above study $27(38.5 \%)$ had feature of liver cirrhosis, $11(15.7 \%)$ had other findings than cirrhosis and $32(45.7 \%)$ patient had normal study on ultrasonography of abdomen. In the above study maximum patient had oesophageal varices $26(37.1 \%)$ as the cause of bleeding followed by duodenal ulcer and erosive mucosal disease $11(15.7 \%)$ each. Gastric ulcer were the cause on $8(11.4 \%)$ patients and esophagitis were present on 7 (10\%). Portal gastropathy was present on 5 (7.1\%) and tumors on 2 (2.8\%). Esophageal varices were present maximum in age group 51-60 year. Average duration of stay in hospital was 8.2 days. The minimum and maximum duration of hospital stay were 4 and 20 days respectively. 41(58.5\%) improved with medication and $25(35.7 \%)$ patients required endoscopic intervention in form of banding, sclerotherapy, Out of 70 patients $2(2.8 \%)$ were referred and another $2(2.8 \%)$ patient expired. 
CONCLUSION: The above study conducted over a span of one year from $1^{\text {st }}$ June 2010 to $31^{\text {st }}$ May 2011 among the patient of upper gastrointestinal bleeding has revealed that esophageal varices was the commonest cause of upper gastrointestinal bleeding in Sikkim. It is followed by peptic ulcer disease and erosive mucosal disease. Increasing trend of esophageal varices is probably due to alcohol abuse leading to alcoholic cirrhosis and various other causes. In addition to that due to overuse of proton pump inhibitors and declining $\mathrm{H}$. pylori infection has decreased the prevalence of peptic ulcer disease as compare to some study from western countries.

Upper gastrointestinal endoscopy was able to identify bleeding in most of the patients if done within 12-48 hours. Endoscopy can be used as diagnostic as well as therapeutic measures. It is therefore recommended that, early endoscopy should be performed preferably within 24 hours of bleeding. Endoscopic treatment was successful in most cases besides conservative treatment. The high prevalence of variceal bleeding and underlying chronic liver disease might explain the increased length of hospital stay and mortality. Further identification of subsets of patients with a high-risk, based on a standardized protocol, may contribute to an improved management of upper gastrointestinal bleeding, including early definition of the most appropriate therapeutic intervention according to local conditions.

Acute upper gastrointestinal bleeding due to peptic ulcer disease can be prevented through strict and judicious use of aspirin and NSAIDs, eradication of $\mathrm{H}$. pylori infection and antiulcer therapy should be given in high risk patients who need chronic NSAIDs or aspirin therapy. Avoidable risk factors particularly alcoholism, smoking, NSAIDS should be curtained down. Early interruption of risks factors will significantly reduces the burden of morbidity and mortality due to upper gastrointestinal bleeding.

\section{REFERENCES:}

1. Juthaba R, Jensem DM,. Acute Upper Gastrointestinal Bleeding, in: Friedman SL, Mc Quaid KR, Grendell JH (eds), Current Diagnosis \& Treatment in Gastroenterology 2nd edition inc 2003; 53.

2. Loren L. Gastrointestinal bleeding. In: Braunwald E, Fauci AS, Dasper DL, Hauser SL, Longo DL, Jameson JL (editors). Harrison's Principle of Internal medicine. USA: McGraw-Hill Companies Inc; $2005: 235$

3. Silverstein FE, Gilbert DA, Tedesco FJ et al. The national ASGE survey on upper gastrointestinal bleeding. I. Study design and baseline data. Gastrointestinal Endoscopy. 1981; 27:73-9.

4. Longstrenth GF: Epidemiology of hospitalization for acute upper gastrointestinal hemorrhage: A population based study. AMJ Gastroenterol 1995; 90:206.

5. Jeff WJ In: Gastrointestinal Bleeding; in the Washington Manual of Medical Therapeutics University School of Medicine, St. Louis, Missouri; Lippincott. Raven Publishers, Philadelphia, and New York 1998; 302-9.

6. Laine Loren; Gastrointestinal bleeding, in Braunwald E, Fauci AS, Dasper DL, Hauser SL, Longo DL, Jameson JL(eds) Harrison's Principle of Internal Medicine, McGraw-Hill Companies Inc. 2005:235.

7. Rockall TA, Logen RF, Devlin HB, Northfield TC: Incidence of and mortality from acute gastrointestinal hemorrhage in the United Kingdom. Steering Committee \& members of National Audit of Acute Upper Gastrointestinal hemorrhage.Br Med J 1995; 311:222. 


\section{ORIGINAL ARTICLE}

8. Vreeburg EM, Snel de Bruijne JW, et al: Acute upper gastrointestinal bleeding in the Armsterdm area: Incidence, diagnosis,\& clinical outcome. Am J Gastroenterol 1997; 92:236.

9. Rosen AM, Fleischer DE: Upper Gastrointestinal bleeding in the elderly: Diagnosis \& Management. Geriatics 1989; 44:26.

10. Yavorski RT, Wong RK, Maydonovitch C, Battin LS, Furnia A, Amundson DE. Analysis of 3,294 cases of upper gastrointestinal bleeding in military medical facilities. Am J Gastroenterol. Apr 1995; 90(4):568-73.

11. Pilotto A, Maggi S, Noale M, Franceschi M, Parisi G, Crepaldi G. Development and validation of a new questionnaire for the evaluation of upper gastrointestinal symptoms in the elderly population: a multicenter study. J Gerontol A Biol Sci Med Sci. Feb 2010; 65(2):174-8.

12. Laine L. Acute and chronic Gastrointestinal Bleeding. Chapter 14 of liver disease by Sleisenger and Fordmans, WB Sunders company Philidelphia $6^{\text {th }}$ Edition Volume 1, 1998; 198-219.

13. Gostout CJ. Acute gastrointestinal bleeding-a common problem revisited. Mayo Clin Proc 1988; 63:596-604.

14. Larson G, Schmidt T, Gott J, et al. Upper gastrointestinal bleeding. Predictors of outcome. Surgery 1986; 100:765-772.

15. Fleischer D. Etiology and prevalence of severe persistent upper gastrointestinal bleeding. Gastroenterology 1983; 84:538-543.

16. Larson DE, Farnell MB. Upper gastrointestinal hemorrhage. MayoClin Proc 1983; 58:371-387.

17. Sugawa C. Endoscopic diagnosis and treatment of upper gastrointestinal bleeding. Surg Clin of North Am 1989; 69:1167-1183.

18. Apel D; Reimann JF, Emergency endoscopy. Can J Gastroenterology 2000 Mar; 14(3):199-203.

19. Yavorski RT, Wong RK, Maydonovitch C, Battin LS, Furnia A, Amundson DE. Analysis of 3,294 cases of upper gastrointestinal bleeding in military medical facilities. Am J Gastroenterol. Apr 1995; 90(4):568-73.

20. Pilotto A, Maggi S, Noale M, Franceschi M, Parisi G, Crepaldi G. Development and validation of a new questionnaire for the evaluation of upper gastrointestinal symptoms in the elderly population: a multicenter study. J Gerontol A Biol Sci Med Sci. Feb 2010; 65(2):174-8.

21. M Uddin Ahmed, M Abdul Ahad, M A Alim, A R M Saifuddin Ekrim, Q Abdulla Al Masum, Sumona Tanu, Refaz Uddin; Etiology of Upper Gastrointestinal Haemorrhage in a Teaching Hospital; The Journal of Teacher Association RMC, Rajshahi; TAJ June 2008; vol 21 number 1.

22. Rajesh Kasyap, Sanjay Mahajan, Brij Sharma, Parmod Jaret, Ramesh K umar Patial, Suresh Rana, Lal Singh Pal; A Clinical Profile of Acute Gastrointestinal Bleeding at Moderate Altitute; JIACM; 6(3):224-8.

23. Gurung RB, Joshi G, Gautam N, Pant P, Pokrel B, koju R, Bedi TRS; Upper gastrointestinal bleeding: Aetiology and demographic profile based on endoscopic examination at Dhulikhel Hospital, Katmandu University Hospital; Katmandu University Medical Journal 2010;Vol. 8, No. 2, issue 30: 208-211.

24. H. Jaka, Mheta Koy, A. Liwa, R. Kabangila, M. Mirambo, W. Scheppach, E. Mkongo, M.D. Mchembe, P. L. Chalya; A fibreoptic endoscopic study of upper gastrointestinal bleeding at bugando medical centre in northwestern Tanzania: A retrospective review of 240 cases; BMC Research Notes 2012, 5:200. 


\section{ORIGINAL ARTICLE}

25. Sugawa C. Endoscopic diagnosis and treatment of upper gastrointestinal bleeding. Surg Clin of North Am 1989; 69:1167-1183.

26. Jutabha R, Jensen DM. Management of upper gastrointestinal bleeding in the patient with chronic liver disease. Med Clin North Am 1996; 80:1035.

27. Hunt RH, Malfertheiner P, Yeomans ND, et al. Critical issues in the pathophysiology and management of peptic ulcer disease. Eur J Gastroenterol Hepatol 1995; 7:685.

28. Hallas J, Lauritsen J, Villadsen HD, Gram LF. Nonsteroidal anti-inflammatory drugs and upper gastrointestinal bleeding, identifying high-risk groups by excess risk estimates. Scand J Gastroenterol 1995; 30:438.

29. Tsesmeli NE. Incidence and aetiology of acute non-malignant upper gastrointestinal bleeding in northern Greece. J Gastroenterol Hepatol Jul 2007; 22:1009-13.

30. DanielL, Worthley, Registrar, Robert J. Management of acute bleeding in the upper gastrointestinal tract. Aust Prescr2005; 28:62-6.

31. Golánová J. Acute haemorrhage of the upper part of the gastrointestinal tract survey of emergency endoscopy of the upper gastrointestinal tract at our facility. Vnitr Lek. 2004 Apr; 50:259-61. 